\title{
GÊNERO E EXECUÇÃO PENAL: A Invisibilidade de Homens Transexuais Encarcerados como uma Ofensa aos Direitos Humanos
}

\author{
Vanessa de Sousa Soares \\ Autora correspondente. Pontifícia Universidade Católica de Minas Gerais - Coração Eucarístico. Av. Dom José Gaspar, 500. \\ Belo Horizonte/MG, Brasil. CEP 30535-610. http://lattes.cnpq.br/5143274583686107. https://orcid.org/0000-0002-8350-6036. \\ vsousasoares@gmail.com
}

Klelia Canabrava Aleixo

Pontifícia Universidade Católica de Minas Gerais. Belo Horizonte/MG, Brasil.

O presente artigo propõe analisar como a Execução Penal lida com as demandas e as especificidades dos homens transexuais encarcerados, tendo em vista que o sistema prisional, projetado e construído de acordo com uma binariedade heteronormativa rígida, não consegue atender às novas demandas, principalmente aquelas relacionadas às identidades de gênero. Nesse sentido, pretendemos investigar como o cárcere e a sua estrutura são empregados ainda como uma forma de disciplinarização que incide diretamente nos corpos, e como as sexualidades e gêneros, considerados destoantes, seriam também atingidos por uma prática de docilização. A pesquisa fará uso de uma metodologia interdisciplinar por meio de um levantamento de fontes bibliográficas, mesclando obras de autores estudiosos da pena e da execução penal e da temática de gênero, destacando-se, nesse momento, Judith Butler. O método histórico-dialético será adotado sob uma abordagem qualitativa com o objetivo descritivo-exploratório. $\mathrm{O}$ artigo limita-se a estudar os homens trans em situação de cárcere em razão das peculiaridades que os envolvem. Não considerar as individualidades destas pessoas como um direito constitucional é uma grave ofensa aos Direitos Humanos.

Palavras-chave: execução penal; direitos humanos; gênero; homens transexuais presos.

\section{GENDER AND PENAL EXECUTION:}

THE INVISIBILITY OF IMPRISONED TRANGENDER MEN AS AN OFFENSE TO HUMAN RIGHTS ABSTRACT

This article proposes to analyze how the Penal Execution deals with the demands and specificities of imprisoned transsexual men, since the prison system, designed and constructed according to a rigid heteronormative binarity, fails to meet the new demands, especially those related to gender identities. In this sense, we intend to investigate how the jail and its structure are still used as a form of disciplinarization that directly affects the bodies and how the sexualities and gender considered as disoriented would also be affected by a docilization practice. The research will make use of an interdisciplinary methodology, through a survey of bibliographical sources, merging works of authors of the pen and criminal execution and the theme of gender, highlighting, at that moment, Judith Butler. The historical-dialectical method will be adopted under a qualitative approach with the descriptive-exploratory objective. The article limits itself to studying trans men in jail because of the peculiarities that surround them. Not considering the individualities of these people as a constitutional right is a serious offense against Human Rights.

Keywords: penal execution; human rights; gender; imprisoned trangender men. 


\section{INTRODUÇÃO}

O presente texto, partindo da configuração atual do modelo de Execução Penal, pretende discutir a tentativa do Direito em oferecer respostas adequadas às demandas da atualidade, sobretudo as referentes aos homens trans encarcerados.

O trabalho justifica-se, pois está alinhado a discussões contemporâneas urgentes relacionadas à diversidade de gênero e à luta pelo reconhecimento de direitos e o respeito às múltiplas identidades inseridas na sociedade. Em atenção a essa diversidade, é de suma importância repensar a estrutura do cárcere, de forma que ele não mais segmente os corpos sob a ótica de um esquema dicotômico justificado na binariedade homem/mulher.

A preocupação gira em torno do tratamento empregado pelo sistema punitivo à população carcerária de homens trans que, por não atender suas necessidades particulares, torna ainda mais latentes as discrepâncias e, por conseguinte, a discriminação seguida de retaliações e violência. Agindo dessa forma, o aparato jurídico contribui para a manutenção de um modelo segregador.

O trabalho detém-se à parcela encarcerada de homens trans em razão das suas necessidades e dificuldades particulares. Tais peculiaridades não poderiam ser analisadas com tanta cautela se a proposta englobasse também travestis e mulheres transexuais em cumprimento de pena.

Partindo do Direito Penal, no âmbito da Execução Penal, portanto, o objetivo principal aqui é compreender as complexidades que cercam o cumprimento de pena de homens trans nos estabelecimentos prisionais.

Assim, para melhor compreensão da discussão, em um primeiro momento será feita uma retomada da aplicabilidade da pena ao longo da história, pelo abandono dos castigos físicos e a eleição do cárcere como nova forma de aplicação da pena no período da modernidade. Isso será feito para entender como as prisões ainda podem ser utilizadas como uma forma de disciplinarização que se aplica sobre o próprio corpo para estabelecer uma relação de docilidade-utilidade, alertando para o descumprimento do Princípio da Individualização da Pena. Logo em seguida, no terceiro capítulo, propõe-se um estudo sobre gênero na Execução Penal e como ele também pode ser usado para regulação e docilização de corpos. O último capítulo será dedicado à análise da situação dos homens transexuais inseridos no sistema carcerário, fazendo um exame sob a égide dos preceitos dos Direitos Humanos.

A presente pesquisa desenvolve-se a partir da concepção de Michel Foucault sobre as relações entre corpo e poder. Além disso, considerando que a ciência jurídica é essencialmente histórica e exige a interdisciplinaridade com outras áreas para ser mais bem entendida, esta pesquisa consultará fontes de outras disciplinas e áreas do conhecimento. Nesse sentido, na interface relativa às discussões de gênero, destacam-se os escritos de Judith Butler. A metodologia utilizada é construída pelo método histórico-dialético, considerando, quanto à abordagem, o seu caráter qualitativo e, quanto aos objetivos, uma roupagem descritivo-exploratória.

\section{A PENA COMO MECANISMO DE MÚLTIPLOS CONTROLES}

Após o trânsito em julgado de uma sentença condenatória, a fase de conhecimento do processo extingue-se e passa a operar a fase executória, momento em que a pena determinada pela autoridade judicial deverá ser cumprida pelo condenado. 
Neste momento, inicia-se uma importante discussão sobre as finalidades da pena. Três teorias a respeito destas finalidades podem ser apontadas, sendo elas: a) a teoria absoluta, que identifica a pena como um fim em si mesma, considerada tão somente como um castigo em consequência ao crime cometido, como uma forma de fazer justiça; b) a teoria relativa, que visa à prevenção de novos delitos e impedir a reincidência ao crime e; c) a teoria mista, que tem o intuito de unir as duas outras teorias, punindo o criminoso pelo mal causado e prevenindo novas condutas delituosas (ROIG, 2014, p. 16).

Muito além dessas três teorias, todavia, a pena teve modificada, ao longo dos anos, a sua aplicabilidade e função. Michel Foucault (2012), em "Vigiar e Punir", fez uma investigação no sentido de entender como a pena foi aplicada nos diversos sistemas punitivos que passaram pela história. Em primeiro lugar, ele distinguiu os modelos de punição e analisou o abandono dos castigos físicos e das mutilações, que dão lugar a uma forma diversa de aplicação da pena:

\begin{abstract}
A punição vai se tornando, pois, a parte mais velada do processo penal, provocando várias consequências: deixa o campo de percepção quase diária e entra no da consciência abstrata; sua eficácia é atribuída à sua fatalidade, não à sua intensidade visível; a certeza de ser punido é que deve desviar o homem do crime e não mais o abominável teatro; a mecânica exemplar da punição muda as engrenagens. Por essa razão, a justiça não mais assume publicamente a parte de violência que está ligada a seu exercício. $O$ fato de ela matar ou ferir já não é mais a glorificação de sua força, mas um elemento intrínseco a ela que ela é obrigada a tolerar e muito lhe custa ter que impor. As caracterizações da infâmia são redistribuídas: no castigo-espetáculo um horror confuso nascia do patíbulo; ele envolvia ao mesmo tempo o carrasco e o condenado: e se por um lado sempre estava a ponto de transformar em piedade ou em glória a vergonha infligida ao supliciado, por outro lado, ele fazia redundar geralmente em infâmia a violência legal do executor. Desde então, o escândalo e a luz serão partilhados de outra forma; é a própria condenação que marcará o delinquente com sinal negativo e unívoco (...) (p. 14-15, grifo nosso).
\end{abstract}

Nesse sentido, ainda que o castigo físico tenha sido abandonado, Foucault considera que não é possível entender as novas configurações de poder sancionador sem compreendê-lo como uma forma de poder que se aplica sobre o próprio corpo. Isso porque o corpo está diretamente imerso no campo político e nas relações de poder e dominação, e só pode ser considerado útil quando se torna produtivo e submisso e "essa sujeição não é obtida só pelos instrumentos da violência ou da ideologia (...) pode ser calculada, organizada, tecnicamente pensada, pode ser sutil, não fazer uso de armas nem do terror, e no entanto continuar sendo de ordem física" (FOUCAULT, 2012, p. 29).

A essa sistemática, Foucault (2012) denomina "tecnologia política do corpo":

Essa tecnologia é difusa, claro, raramente formulada em discursos contínuos e sistemáticos; compõe-se muitas vezes de peças ou de pedaços; utiliza um material e processos sem relação entre si. O mais das vezes, apesar da coerência de seus resultados, ela não passa de uma instrumentação multiforme. Além disso seria impossível localizá-la, quer num tipo definido de instituição, quer num aparelho do Estado. Estes recorrem a ela; utilizam-na, valorizam-na ou impõem algumas de suas maneiras de agir. Mas ela mesma, em seus mecanismos e efeitos, se situa num nível completamente diferente. Trata-se de al- 
guma maneira de uma microfísica do poder posta em jogo pelos aparelhos e instituições, mas cujo campo de validade se coloca de algum modo entre esses grandes funcionamentos e os próprios corpos com sua materialidade e suas forças (p. 29, grifo nosso).

Considerando que o corpo é uma figura política, ele é disciplinado e usado como meio de controle na produção de corpos dóceis e padronizados de acordo com a aceitação social. Foucault (2012) define essa prática de docilização de corpos como sendo uma "anatomia política", característica da intervenção penal moderna, que se desenvolve a partir de uma série de práticas de coerções com a finalidade de moldar os corpos e, nesse sentido, "o corpo humano entra numa maquinaria de poder que o esquadrinha, o desarticula e o recompõe" (p. 133).

Com o abandono do suplício corporal e dos ferimentos físicos, o cárcere fora eleito no período da modernidade como espectro disciplinar e de controle. Assim, as prisões teriam o intuito de eliminar aqueles que de qualquer forma não se conformam com a norma:

(...) a prisão pode ser vista como uma estrutura preocupada justamente em dar conta das sobras do processo de controle da violência, monopolizando a violência e a lei. Naquele momento, o controle social estava direcionado àquelas pessoas que apresentavam dificuldades de se inserirem no processo produtivo emergente e não se enquadravam nem como trabalhadores, nem como carentes, e precisavam ser, por isso, disciplinadas. A essa sobra da sobra, a prisão passou a ser alternativa (WOLFF; FERREIRA, 2011, p. 48).

Em linhas gerais, as prisões tornaram-se, no período da modernidade, um meio de domesticação de corpos e, nesse sentido, "tipos" seriam escolhidos para se transformarem em dóceis.

Na contemporaneidade, o controle social por meio da prisão não tem como característica principal a normalização mediante a disciplina. Seu objetivo central é a neutralização das classes perigosas.

A busca pela reforma do indivíduo, todavia, não foi abandonada por completo na prisão. Está aliada a outras tecnologias de poder:

A coexistência entre os modelos disciplinar, biopolítico e de controle é, pois, característica das sociedades ocidentais contemporâneas que têm altas e crescentes taxas de encarceramento aliadas a mecanismos de vigilância a céu aberto. Há também o exercício do poder tanto sobre o corpo individual como sobre a população (ALEIXO, 2012, p. 73).

Esse entrelaçamento entre as tecnologias de poder configura um campo híbrido que tanto dificulta a identificação de suas manifestações no campo social quanto constitui um desafio na árdua tarefa de se pensar como deve ser uma intervenção capaz de desconstituir tais relações de poder (ALEIXO, 2012, p. 75).

\subsection{A inaplicabilidade do Princípio da Individualização da Pena na fase de Execução Penal}

Baratta (2002) explica o processo de seletividade penal que se desenvolve a partir da criminalização de determinadas classes consideradas inferiores que são pensadas como lesivas às classes dominantes. De acordo com Zaffaroni (2001), o Estado seleciona, já por meio da legislação, os indivíduos que serão submetidos à sua coação e a suas penas.

Considerando que as prisões foram eleitas como mecanismos oficiais de aplicação da pena, tornou-se urgente, diante das novas demandas, reconhecer a autonomia do Direito de 
Execução Penal. Priorizando o exercício de uma jurisdição especializada, a Lei de Execuções Penais $(L E P)^{1}$ foi criada para propor uma rede de princípios e regras que jurisdicionalizem a execução das penas, na tentativa de avalizar direitos e garantias ao sentenciado.

Vários princípios são elencados na LEP com o intuito de certificar que o condenado conserve todos os seus direitos não atingidos pela sentença penal. Nesse sentido, a norma legal garante ao sentenciado que os efeitos da condenação não deverão, de qualquer forma, atingir outros direitos senão àqueles ligados à sua liberdade ambulatorial. Em resumo, por mais que o indivíduo esteja em privação de liberdade, seus direitos devem permanecer intocados.

Ainda que, todavia, a LEP preveja um rol de garantias com o cuidado de não suspender ou restringir os direitos individuais, muitos dos princípios constitucionais inseridos na lei estão sendo descumpridos ou desconsiderados, como o da Individualização da Pena. Em razão disso, diversos direitos dos sujeitos em cumprimento de pena estão sendo mitigados.

O Princípio da Individualização da Pena, estabelecido na Constituição Federal (artigo 50, $\mathrm{XLVI}$ ), preconiza "que as autoridades responsáveis pela execução penal possuem a obrigação de enxergar o preso como verdadeiro indivíduo, na acepção humana do termo, considerando suas reais necessidades como sujeito de direitos" (ROIG, 2014, 46). De acordo com esse princípio, portanto, é garantido aos indivíduos, no momento da condenação, que a sua pena seja individualizada, levando em consideração as peculiaridades aplicadas a cada caso, que vai determinar um cumprimento individualizado da sanção aplicada. As autoridades administrativas e judiciais devem se atentar às demandas daquele que foi sentenciado, evitando qualquer tratamento discriminatório.

Assim, considerando o Princípio da Individualização da Pena, certo é que as particularidades de cada caso devem ser consideradas para que não só a aplicação da pena seja justa, mas também o seu cumprimento.

Pautado sob um discurso de ressocialização, porém, o sistema de execução penal "parece fazer parte de um mecanismo de violência institucionalizada, operacionalizada pelo poder punitivo a impor a reforma da personalidade como forma de aniquilamento da individualidade do preso" (ALEIXO; PENIDO, 2018, p. 25). Dessa maneira, relacionando com a concepção foucaultiana, há a imposição de um pensamento de que, para estar apto a voltar ao convívio social, o preso deve repetir uma série de comportamentos impostos e, consequentemente, abandonar a sua personalidade e individualidade, de forma a docilizar os corpos.

A respeito da neutralização da pessoa presa, Klelia Canabrava Aleixo e Flávia Ávila Penido (2018) dissertam:

Verifica-se que o objetivo da execução penal de "harmônica integração social" pressupõe a existência de uma sociedade integrada, harmonicamente, modelo ao qual o condenado deve se "integrar" sem maiores questionamentos. Ocorre que esta sociedade não existe e tal finalidade viabiliza a homogeneização de comportamentos aos valores dominantes, ignorando a alteridade. Verifica-se também que a violência absoluta - presente no ambiente carcerário - é quase sempre a razão para o "convencimento do preso a se ressocializar, o que também configura violência ilegítima (ALEIXO; PENIDO, 2018, p. 33-34, grifo nosso).

Lei $n$ ㅇ 7.210, de 11 de julho de 1984. 
Nesse sentido, contrariando abertamente o Princípio da Individualização, a pena aplicada na fase de Execução Penal tem sido utilizada como um meio de contenção e neutralização do condenado, apagando a sua personalidade para a produção de corpos dóceis. É nessa esteira que se torna necessário analisar a dinâmica da Execução Penal sob o viés das transexualidades, sobretudo das individualidades dos homens trans encarcerados.

\section{AS DISCUSSÕES DE GÊNERO NA FASE DE EXECUÇÃO PENAL}

As pesquisadoras Angela Marques e Ana Luisa Mayrink (2016), partindo da concepção de Judith Butler, entendem que o gênero também é produto de um código social instituído usado para a regulação de corpos, e todo aquele que não se conforma à norma torna-se vulnerável a coerções de diversas ordens. Nesse sentido, as subjetividades são também atingidas pela prática de disciplinamento, docilização e normalização dos corpos. Conforme discute também Miskolci (2006),

Percebe-se, assim, que o espaço de problematização das relações entre corpo e identidade é maior do que parece à primeira vista, pois vai muito além das técnicas corporais propriamente ditas e alcança as formas como compreendemos a nós mesmos e, sobretudo, a forma como somos levados a ver o outro (p. 682).

Zygmunt Bauman (1998) afirma que a modernidade não abandonou antigos ideais de beleza, pureza e ordem. Cada época e cultura teriam um padrão ideal a ser mantido e todo aquele que for destoante à ordem outrora estabelecida é visto como um empecilho à higiene. Nesse sentido, existe uma hierarquização social que é mantida e naturalizada não só pelo Direito, mas também pela dinâmica social cotidiana.

Nessa esteira, as sexualidades e gêneros considerados destoantes seriam "alvos" no sistema penal. Judith Butler (2001) conceitua gênero como o instrumento que se materializa nos corpos, pelo qual os sujeitos são identificados, classificados e, portanto, conformados. Sobre o gênero também recai uma normatividade, um padrão socialmente aceito, que indica que ele sempre deve estar em conformidade com o sexo, e todo aquele que não se enquadre nesse padrão será passível de exclusão.

Em outras palavras, o ideal normativo, no que diz respeito às questões de gênero, manifesta-se, também, pelo corpo. Remedios Bravo (2018), fazendo uma análise de Butler, explica que, ao exigir essa conformidade dos corpos ao gênero, é mantida uma matriz normativa que reafirma um padrão binário rigoroso, sustentando um arquétipo de feminilidade e masculinidade que reafirma a heterossexualidade em suas práticas:

Como Butler insiste, o fundamental é que nossa inteligibilidade social depende, em última instância, dessas relações de poder. Então, seremos mais ou menos reconhecíveis para os outros, dependendo de como somos acomodados às regras normativas às quais estamos sujeitos. E será essa adequação que determinará as condições materiais, como a segurança ou bem-estar, da nossa própria vida. Vamos dizer que esta é a nova forma de violência que inaugura a disciplina, que, apesar de não punir fisicamente o corpo, obriga os indivíduos a incorporar uma lei que os torna socialmente inteligíveis. O poder determina, portanto, nosso status ontológico, causando que qualquer desidentificação com a lei implica uma expulsão da esfera do real (BRAVO, 2018, p. 72, tradução nossa). 
Essa dificuldade em compreender e acolher as diversidades não é percebida somente na sociedade, mas também no plano jurídico. O Direito moderno fala sobre igualdade, determinando que todos são iguais perante a lei. Ao estabelecer, todavia, puramente uma isonomia, "o Estado é cego às diferenças, (...) supõe a construção de um tipo ideal de indivíduo, tomado a priori como ideal/normal/legal-legítimo/são" (BAHIA, 2017, p. 497, grifo do autor).

Hodiernamente, ainda que se perceba uma tentativa do Direito em abarcar as diferenças, especificamente no campo das políticas LGBT+, o que se vê é a tentativa de ajustar os diferentes em padrões já existentes, sem reconhecer de fato que nem todos se ajustam ao esquema binário-heteronormativo. Nesse sentido, Alexandre Bahia (2017) articula:

Fala-se muito nos tempos de hoje em diversidade e pluralidade, inclusive no âmbito do Direito. No entanto, pelo menos quanto a esse ramo do conhecimento, muito pouco houve de mudanças para que ele possa, de fato, reconhecer a naturalidade da diversidade. E fala-se em diversidade, e não em diferença; em reconhecimento, e não tolerância, porque esta e aquela ainda partem da ideia típica da modernidade de que há um padrão, apenas que agora se permite que o outro exista. Ao revés, aqui se faz referência ao reconhecimento de que nem todos são iguais, que dificilmente caberiam em caixas conceituais, pois que elas sempre são reducionistas da complexidade da existência humana. A diversidade, então, também é uma variante da igualdade, ao lado de isonomia e equidade, e certamente é um dos maiores desafios para o Direito dos dias de hoje (p. 499, grifo do autor)

Baratta (1999) sustenta que a Constituição estabelece a igualdade formal, mas para torná-la real é necessária uma igualdade material que afaste as discriminações que impõem modelos e esmagam ou eliminam as diferenças. É preciso que o Direito reconheça que existem sujeitos que não se enquadram na normativa de gênero, como é o caso dos homens trans. $\mathrm{Na}$ execução penal não é suficiente o desenvolvimento de políticas de acolhimento de homens trans que se baseiem puramente em um caráter performativo masculino/feminino, pois "é preciso romper com o gênero no direito e abandonar os essencialismos de sua divisão binária artificial".

Ainda, portanto, que exista uma Resolução Conjunta (Resolução 15 de abril de 2014) estabelecendo parâmetros para o acolhimento da população LGBT+ no cumprimento de pena privativa de liberdade, faz-se mister ressaltar que ela é uma resolução simplista de uma questão muito mais complexa. Além disso, sua aplicação ainda não é eficaz e muitos estabelecimentos prisionais não fazem uso dela.

A Resolução foi baseada em diversos dispositivos legais, como o artigo 50 da Constituição Federal e a Declaração dos Direitos Humanos, em uma tentativa de melhorar o cumprimento de pena das pessoas LGBT+. Dentre as diversas diretrizes, a Resolução prevê que os apenados travestis e transexuais têm o direito de ser chamados pelo seu nome social, devendo ser facultado o uso de roupas masculinas ou femininas e a manutenção de cabelos compridos, de acordo com a identidade de gênero. Além disso, a Resolução prevê, inclusive, o direito à visita íntima.

Em relação aos homens transexuais, objeto deste estudo, a portaria faz menção a eles no artigo 4음 nos seguintes dizeres: "as pessoas transexuais masculinas e femininas devem ser encaminhadas para as unidades prisionais femininas". 
O que se percebe da leitura do artigo 4ㅇ é a incapacidade do aparato jurídico em reconhecer a diversidade que escapa da dinâmica legalista do Direito. Pautado sob a ótica de um sistema homogeneizante e à égide de um aparelho normativo construído em cima de normalidades, o Direito se vê diante de uma juridicidade que se regula "na inclusão gerando a exclusão e a dificuldade de pensar para além de caixas conceituais com as quais tenta aprisionar a realidade" (BAHIA, 2016, p. 488).

A anatomia do cárcere já sugere o perpetuamento de uma dinâmica disciplinar pautada sob uma base heteronormativa e definida sob o contexto do binarismo homem/mulher.

A título de exemplo, em junho de 2019 Luís Roberto Barroso, ministro do Supremo Tribunal Federal (STF) ${ }^{2}$, em decisão liminar, determinou a transferência para estabelecimentos femininos de todas as mulheres transexuais que estivessem cumprindo pena em presídios masculinos. Essa medida foi tomada para preservar a saúde física e psicológica das detentas. Na decisão, o ministro definiu tratar-se "da única medida apta a possibilitar que (as mulheres trans) recebam tratamento social compativel com a sua identidade de gênero. Trata-se, ademais, de providência necessária a assegurar a sua integridade física e psíquica, diante do histórico de abusos perpetrados contra essas pessoas em situação de encarceramento".

Transferir as mulheres transexuais para um local que se adequasse à sua identidade de gênero foi a resposta encontrada pelo poder público para resolver, ainda que de forma temporária, a questão.

Por outro lado, se fosse analisar a situação de homens trans, essa solução possivelmente não seria a mais adequada. Isso porque a transferência desses sujeitos para estabelecimentos prisionais masculinos poderia resultar em danos irreparáveis a eles. Nesse sentido, alternativa distinta teria de ser pensada pelo Direito para atender às suas demandas. Isso porque transferir homens trans para presídios masculinos seria o mesmo que condená-los a uma pena aquém da estipulada em sua sentença.

O poder público visualizou a problemática de transferir os homens transexuais para penitenciárias masculinas, tanto é que no artigo 4 으 da Resolução optou por mantê-los nas femininas. Isso, porém, não seria o mesmo que ignorar a existência e a identidade de gênero dessas pessoas? A impressão que fica é que não conseguiram pensar no que fazer com essa parcela prisional e acabaram deixando de lado suas necessidades e peculiaridades.

Um dos argumentos utilizados pelo ministro para determinar a transferência de travestis para um estabelecimento prisional feminino foi "o respeito à sua identidade de gênero". É necessário ter cautela ao fazer uso desse tipo de discurso, uma vez que, como dito anteriormente, não seria possível utilizar o mesmo argumento para transferir homens trans para presídios masculinos.

No cenário brasileiro, a vivência dos homens trans, quando não é invisível, é permeada por preconceitos e discriminações, realidade que não se diferencia muito no contexto carcerário. Judith Butler (2003) explica que, por não se encaixarem nos parâmetros heterocentrados, esses sujeitos possuem um estigma que os impede de ser vistos e entendidos como humanos. Nesse sentido, nasce um desejo de "normalizar" esses indivíduos. Isso acontece, dentre ou- 
tras razões, porque o corpo é utilizado como uma forma de controle e, por meio de diversos métodos, são impostos a estes corpos uma relação de docilidade-utilidade (FOUCAULT, 2012).

Nesse contexto, os homens trans se veem diante de uma rede de exclusão (PRADO; JUNQUEIRA, 2011) que se caracteriza pela privação de acolhimento tanto familiar e da sociedade quanto das instituições públicas. Isso ocorre nos estabelecimentos prisionais na medida em que o tratamento reservado a esses sujeitos é baseado em uma "política das coerções que são um trabalho sobre o corpo, uma manipulação calculada de seus elementos, de seus gestos, de seus comportamentos" (FOUCAULT, 2012, p. 133).

Sob a perspectiva de Salo de Carvalho, Guilherme Gomes Ferreira (2015), em seu estudo sobre travestis e prisões, discorre sobre as dificuldades enfrentadas pelos sujeitos destoantes ao modelo de padrão de sexualidade e de gênero, afirmando que "os desejos e prazeres dissidentes, quando ingressam nos sistemas punitivos, experimentam padrões distintos e únicos de controle e repressão, na forma de criminalização e também patologização" (FERREIRA, 2015, p. 1.790).

A partir da discussão de Miskolci sobre a docilização de corpos, no sentido de que "as técnicas de disciplina corporal são assujeitadoras porque criam não apenas corpos padronizados, mas também subjetividades controladas" (MISKOLCl, 2006, p. 682), pode-se pensar como o cárcere, no contexto dos homens trans, é capaz de disciplinar e normatizar seus corpos.

É importante destacar que, nos estabelecimentos prisionais, encaixar os sujeitos em uma estrutura puramente baseada na identidade de gênero não é suficiente. Isso, pois, se assim for feito, as mulheres trans serão transferidas para penitenciárias femininas de acordo com a sua identidade de gênero. Por outro lado, se os homens trans forem transferidos para estabelecimentos prisionais masculinos, também em acordo com a sua identidade de gênero, sofrerão muito além da pena privativa de liberdade que lhes fora imposta. Estupros, retaliações, violências físicas e psicológicas poderão infligi-los. Mantê-los, entretanto, em presídios femininos, conforme prevê o artigo 4ㅇ da Resolução Conjunta, sem que sejam discutidas outras possibilidades de inclusão, seria uma forma de torná-los invisíveis.

É esse o desafio que o Direito contemporâneo precisa enfrentar para que consiga propor soluções que reinventem o modelo atual e superem as concepções binárias e segregantes.

O que se percebe hoje é a transformação da Execução Penal em um campo de exceção. Utilizando os ensinamentos de Giorgio Agamben (2010), durante o cumprimento de pena, não somente em relação às pessoas transexuais, cumpre ressaltar, há uma tentativa de legitimar o poder a partir da suspensão da lei (ou dos direitos), instalando o estado de exceção. Nesse estado, é delimitada uma esfera da vida nua, ou seja, do homo sacer, e uma esfera do político. Assim, aquele que é considerado homo sacer acaba sendo colocado em uma condição matável.

Trazendo mais uma vez à tona a discussão de gênero, em relação aos homens transexuais há a vulnerabilização desses corpos que, transformados em uma espécie de ameaça a ideais fortemente internalizados de uma norma de gênero, tornam-se alvo de toda uma gama de violências físicas e simbólicas que visam a excluir e exterminar essas existências incômodas, transformando-os em subvidas. 
Judith Butler, em sua discussão sobre vidas precárias e vidas passíveis de luto, acrescenta que "se certas vidas não são qualificadas como vidas ou se, desde o começo, não são concebíveis como vidas de acordo com certos enquadramentos epistemológicos, então essas vidas nunca serão vividas nem perdidas no sentido pleno dessas palavras" (BUTLER, 2015, p. 13).

Os discursos encarceradores e a binariedade rígida do cárcere, portanto, parecem legítimos, mas fazem parte de uma técnica de aniquilamento da pessoa presa, ou seja, docilizar os corpos dos sentenciados é o mesmo que acabar com as suas características, com a sua individualidade.

Por fim, percebe-se que o modelo penitenciário brasileiro, com a sua rigidez binária, não está sendo capaz de atender eficazmente a todas as questões e, principalmente, quando diz respeito à discussão das identidades de gênero. Os questionamentos que restam são muitos: Os sentenciados devem ser transferidos às penitenciárias de acordo com a sua identificação de gênero? Essas pessoas devem ser segregadas em espaços LGBT+? Outras "caixinhas" devem ser criadas para tentar se adequar às demandas?

\subsection{Ausência de dados oficiais: a invisibilidade da população transexual como uma ofensa aos Direitos Humanos}

Considerando a problemática do encarceramento de homens transexuais, esta pesquisa atentou-se em buscar dados oficiais que apontassem o número de pessoas LGBT+ aprisionadas para entender, em sua amplitude, a situação. No Brasil, todavia, não existem números sobre essa população; ela não aparece no Levantamento Nacional de Informações Penitenciárias do Ministério da Justiça e Segurança Pública (Infopen). Assim, não existe hoje um banco de dados para saber quantas pessoas LGBT+ estão presas, por que estão presas, quais as experiências de violência que elas sofrem e a sua realidade prisional.

Sabendo dessa circunstância, a ONG Somos, de Porto Alegre, em 2018 iniciou um projeto chamado "Passagens - Rede de Apoio a LGBTs nas prisões" para tentar traçar um censo para aqueles que hoje são invisíveis no sistema penal. Além disso, o projeto também se propõe a mapear a situação do tratamento destinado às pessoas LGBTs presas e a monitorar as informações para propor a criação de espaços específicos para essa população. Essa mesma ONG, ademais, produziu, em maio de 2019, um breve documentário com o intuito de mostrar a realidade de pessoas LGBT+ encarceradas.

O que se percebe da situação narrada é que a população LGBT+, além das violações que sofre com a sua chegada no sistema prisional, está também invisibilizada e esquecida pelo sistema penal, uma vez que não existem sequer dados que sinalizem a sua existência. A preocupação decorre do fato de que se não existem informações dessa parcela populacional, não existem também formas de pensar em políticas públicas para fazer o seu controle e propor melhorias em seu cumprimento de pena.

Nesse sentido, é possível considerar a violência sexual e de gênero não só como um desrespeito aos Direitos Humanos, mas também como apagamento de sua existência.

A estrutura basilar dos Direitos Humanos é a noção de dignidade humana que pode ser definida como as "condições adequadas de existência" (RAMOS, 2005, p. 20). Assim, esses direitos devem ser considerados inerentes à qualidade e à condição de ser humano, indis- 
pensáveis para uma existência digna e para a realização plena do indivíduo, reconhecendo e garantindo seus direitos básicos.

Na legislação brasileira os Direitos Humanos estão previstos, quase que em sua totalidade, no artigo 50 da Constituição Federal, e determinam aqueles direitos inerentes à proteção do indivíduo, fundamentais à pessoa humana e garantias individuais. A preocupação com a proteção dos sujeitos, não só no Brasil, mas também no âmbito internacional, tornou-se latente pós Segunda Guerra Mundial e foi o incentivo para a criação da Declaração dos Direitos do Homem e do Cidadão de 1789, considerada um marco da universalidade dos direitos fundamentais. Em 1948 foi aprovada, ademais, a Declaração Universal dos Direitos do Homem, que valoriza a proteção da tríplice direitos individuais, direitos sociais e direitos difusos.

Apesar de universais, os Direitos Humanos, para serem concretizados, precisam, além de reconhecimento, da jurisdição do Estado, ou seja, assegurar esses direitos significa não somente declará-los, mas pensar em uma nova forma de torná-los eficazes a todos os seres humanos de igual maneira. Nessa direção, Hanna Arendt (1951) defende a ideia de pensar em uma nova lei da humanidade em que todos os indivíduos tenham o direito de ter direitos e de pertencer à humanidade.

As garantias defendidas pelos Direitos Humanos, por outro lado, estão atreladas e influenciadas por contextos sociais e culturais distintos a depender de cada sociedade e às suas singularidades. Dessa forma, esses direitos acabam tornando-se campos de disputas e reivindicações ao redor do mundo, principalmente quando dizem respeito às camadas mais vulneráveis da sociedade. Assim, as minorias encontram nos Direitos Humanos uma forma de afirmação e efetivação dos seus direitos.

É importante frisar que as normas protecionistas, amparadas pelos Direitos Humanos, devem ser abertas e se adequarem continuamente às novas demandas da sociedade e à criação de novos direitos. Nesse sentido,

A conduta adotada de "permitir" que a norma e os comportamentos internos sejam afetados pelos parâmetros internacionais de proteção da dignidade humana, a qual é observada em face da elaboração de novos direitos que, no decurso do tempo, gradativamente, incorporam-se aos sistemas jurídicos diversos, em culturas diferentes, reflete a força expansiva dos Direitos Humanos, que influencia a construção e reconstrução dos ordenamentos jurídicos dos diversos países e propicia o surgimento dos chamados "novos direitos" (SMITH; SANTOS, 2017, p. 1103).

As demandas da população LGBT+ em situação de cárcere requerem a criação desses novos direitos para que garantam a essas pessoas dignidade e manutenção do exercício da sua cidadania. Infelizmente a ausência de dados oficiais que reportem a sua situação no sistema penal só reforça a ideia da invisibilidade que sofrem na sociedade, que provoca inúmeras violações aos Direitos Humanos.

Especificamente em relação aos homens transexuais, o apagamento é ainda mais latente. Isso porque, ao contrário das mulheres transexuais e travestis que são protagonistas de inúmeros debates para decidir a viabilidade da transferência para penitenciárias femininas em respeito à identidade de gênero, os homens trans estão apagados, invisíveis no sistema. 
Não se pretende aqui, de forma alguma, afirmar que mulheres transexuais e travestis estão em uma posição privilegiada socialmente, mas alertar para o silenciamento e o descaso com a parcela de homens transexuais encarcerados.

Hoje, no país, não é possível identificar com clareza quais as necessidades e as dificuldades que homens trans em cumprimento de pena privativa de liberdade enfrentam diariamente, tampouco sua rotina no cárcere. Ademais, também é inimaginável a convivência dessas pessoas com as outras mulheres, companheiras de celas, e qual é o impacto do convívio para ambos e, ainda, sequer, o tratamento recebido por eles dos agentes penitenciários.

\section{CONSIDERAÇÕES FINAIS}

O presente trabalho buscou discutir os padrões de acolhimento de homens transexuais na fase de Execução Penal.

Em um primeiro momento, foi proposta uma breve investigação acerca da trajetória da pena para entender como ela passou de um castigo imposto, por meio de torturas e mutilações, para uma forma mais sutil de correção. Assim, na modernidade, o cárcere passa a ser considerado o meio oficial de aplicação da pena. Foucault, todavia, acredita que estas novas formas do poder sancionador, sob outra roupagem, ainda recaem sobre o próprio corpo; isso porque as prisões tornam-se mecanismos de controle na produção de corpos dóceis e padronizados de acordo com a aceitação social.

Nesse sentido, contrariando o Princípio da Individualização da Pena, assentado na LEP, o cárcere trabalha com o apagamento do sujeito encarcerado, desconsiderando toda a sua individualidade e particularidade com o intuito de eliminar todo aquele que não se conforma com a norma.

Partindo da concepção de gênero de Judith Butler, por ser também produto de um código social instituído usado para a regulação de corpos, o indivíduo, que não se conforma aos padrões de gênero impostos, sofre coerções de diversas ordens. Diante das novas discussões relacionadas à identidade de gênero, surge também uma nova preocupação na Ciência Penal: o cárcere está dando conta dessas demandas e das particularidades dos homens trans encarcerados?

O que se percebe é uma estrutura carcerária rígida baseada em um padrão binário e heteronormativo que não é capaz de lidar com as questões relacionadas à pauta de gênero e não se dá conta de que nem todos se encaixam nos padrões previamente instituídos. Assim, até mesmo as tentativas de inclusão, como a instauração da Resolução Conjunta de 15 de abril de 2014, têm sido feitas de maneira simplista, sob a égide de um discurso impensado e às pressas.

A preocupação gira em torno da parcela encarcerada de homens transexuais em razão do apagamento da sua existência e identidade. $\mathrm{O}$ artigo 4을 da Resolução estabelece que eles devam ser mantidos em estabelecimentos prisionais femininos, e o poder público certamente avaliou e concluiu os ricos de mandá-los para penitenciárias masculinas. Deixá-los, todavia, nas femininas, abandonados à sua sorte, sem acompanhamento de psicólogos e especialistas que estudem os impactos da convivência com as outras mulheres encarceradas, para ambas as partes é irresponsável. Além disso, os homens transexuais, diferente das mulheres transe- 
xuais e travestis que têm, hoje, a sua situação carcerária discutida pelos Tribunais brasileiros, estão esquecidos em suas celas pelo poder público.

Esse trabalho pretendeu questionar a capacidade do Direito Penal, especificamente do cárcere, de absorver e se adequar às novas demandas de gênero e sexualidade. Sabendo da sua falência, deveria ele criar novos espaços para abrigar a diversidade da modernidade em uma pretensa redução de danos? Fala-se em redução de danos porque as penas privativas de liberdade deixaram há muito de ser um meio eficaz de poder sancionador, sendo necessário repensar toda a estrutura punitiva; mesmo porque, sob um viés garantista, o Direito Penal deve agir como instrumento limitador do poder estatal e não como máquina de tortura contra aqueles que descumpriram a lei.

Por fim, além de questionar a estrutura e a eficácia do cárcere, este trabalho pretendeu fazer um alerta sobre uma parcela encarcerada que está esquecida pela sociedade e pelo poder público, tendo sua individualidade apagada e suas demandas desconsideradas: a de homens transexuais.

\section{REFERÊNCIAS}

AGAMBEN, Giorgio. Homo Sacer: o poder soberano e a vida nua I. Tradução de Henrique Burigo. Belo Horizonte: Editora UFMG, 2010.

ALEIXO, Klelia Canabrava. Ato infracional: ambivalências e contradições no seu controle. Curitiba: Juruá, 2012. ALEIXO, Klelia Canabrava; PENIDO, Flávia Ávila. Execução penal e resistências. Belo Horizonte: Editora D’Plácido, 2018.

ARENDT, Hanna. The Origins of Totalitarianism. New York: HBJ, 1951.

BAHIA, Alexandre Gustavo Melo Franco. Sobre a (in)capacidade do direito de lidar com a gramática da diversidade de gênero. In: Revista Jurídica da Presidência, n. 116, v. 18, p. 481-506, 2017.

BARATTA, Alessandro. Criminologia crítica e crítica do direito penal: introdução à sociologia do direito penal. 3 . ed. Rio de Janeiro: Editora Revan; Instituto Carioca de Criminologia, 2002.

BAUMAN, Zygmunt. O mal-estar da pós-modernidade. Rio de Janeiro: Jorge Zahar Editor, 1998.

BRAVO, Remedios. Cuerpo y poder. Una conversación entre Foucault y Butler. In: Dorsal. Revista de Estudios Foucaultianos, n. 4, p. 63-85, 2018.

BRASIL. Constituição da República Federativa do Brasil de 1988. Disponível em: http://www.planalto.gov.br/ccivil_03/Constituicao/Constituicao.htm. Acesso em: 10 set. 2018.

BRASIL. Lei no 7.210 de 11 de julho de 1984. Lei de Execuções Penais. Disponível em: http://www.planalto.gov. br/ccivil_03/LEIS/L7210.htm. Acesso em: 1ㅇs. 2018.

BRASIL. Resolução Conjunta no 1, de 15 de abril de 2014. Diário Oficial da União, n. 74, 17 abr. 2014.

BUTLER, Judith. Quadros de guerra: quando a vida é passível de luto? Rio de Janeiro: Civilização Brasileira, 2015. BUTLER, Judith. Problemas de gênero: feminismos e subversão da identidade. Rio de Janeiro: Civilização Brasileira, 2003.

BUTLER, Judith. Corpos que pesam: sobre os limites discursivos do sexo. Tradução Tomaz Tadeu da Silva. In: LOURO, Guacira Lopes (org.). O corpo educado. Belo Horizonte: Autêntica Editora, 2001.

FERRAJOLI, Luigi. Derechos y garantías. La ley del más débil. 4. ed. Madrid: Editorial Trotta, 2004.

FERREIRA, Guilherme Gomes. Travestis e prisões: experiência social e mecanismos particulares de encarceramento no Brasil. Curitiba: Multideia, 2015.

FOUCAULT, Michel. Vigiar e punir: nascimento da prisão. Trad. Raquel Ramalhete. 35. ed. Petrópolis: Vozes, 2012. GOMES, Camilla de Magalhães. Têmis Travesti: as relações entre gênero, raça e direito na busca de uma hermenêutica expansiva do "humano" no Direito. 2017. 234 f. Tese (Doutorado em Direito) - Universidade de Brasília, Brasília, 2017.

MARQUES, Angela Cristina Salgueiro; MAYRINK, Ana Luisa. A potencialidade das roupas na expressão política e na subjetivação de mulheres trans. In: Revista Novos Olhares, n. 2, v 5, p. 7-24, 2016. 
MISKOLCl, Richard. Corpos elétricos: do assujeitamento à estética da existência. In: Revista Estudos Feministas, Florianópolis, 14(3), p. 27, p. 681-693, set./dez. 2006.

PRADO, Marco Aurélio Máximo; JUNQUEIRA, Rogério Diniz. Homofobia, hierarquização e humilhação social. In: VENTURINI, G.; BOKANY, V. (org.). Diversidade sexual e homofobia no Brasil. 1. ed. São Paulo: Editora Fundação Perseu Abramo, 2011. p. 51-71.

RAMOS, André de Carvalho. Teoria geral dos direitos humanos na ordem internacional. Rio de Janeiro: Renovar, 2005.

ROIG, Rodrigo Duque Estrada. Execução penal: teoria crítica. São Paulo: Saraiva, 2014.

SMITH, Andreza do Socorro Pantoja de Oliveira; SANTOS, Jorge Luiz Oliveira dos. Bodies, identities and violence: the gender and the human rights. Rev. Direito Práx., Rio de Janeiro, v. 8, n. 2, p. 1.083-1.112, June 2017. Disponível em: http://www.scielo.br/scielo.php?script=sci_arttext\&pid=S217989662017000201083\&lng=en\&nrm=iso. Acesso em: 20 jun. 2019.

ZAFFARONI, Eugenio Raúl. Em busca das penas perdidas: a perda da legitimidade do sistema penal. 5. ed. Rio de Janeiro: Editora Revan, 2001.

WOLFF, Maria Palma; FERREIRA, Guilherme Gomes. Vulnerabilidade penal no contexto das penas e medidas alternativas. In: Somos - Comunicação, Saúde e Sexualidade. Construindo Elos: um debate sobre gênero, violência e direitos humanos em penas e medidas alternativas. Porto Alegre: Somos, 2011. p. 47-55. 